\title{
Research on thermal performance of external thermal insulation composite concrete wall block
}

\author{
Chenghua Zhang ${ }^{1 *}$, Jisheng Qiu ${ }^{1}$, Xiao Guan ${ }^{1}$, Piji Hou $^{1}$ and Wei Huang ${ }^{2}$ \\ ${ }^{1}$ Xi'an University of Science and Technology, School of Architecture and Civil Engineering, Department of Mining \\ Construction, Xi'an 710054, China \\ ${ }^{2}$ Xi' an University of Architecture and Technology, School of Civil Engineering, Department of Construction Engineering, Xi'an \\ 710055, China
}

Corresponding Author Email: zch-0819@163.com

https://doi.org/10.18280/ijht.360137

Received: 24 August 2017

Accepted: 12 November 2017

\section{Keywords:}

concrete wall, thermal performance, heat transfer resistance, thermal inertia, $H$ shaped wall block structure

\begin{abstract}
For the defects of temperature control performance and thermal property of existing concrete building walls, a new composite concrete wall block is proposed, and the thermal property of the block is calculated and analyzed. The transverse hole of designed H-shaped concrete block can be embedded with thermal insulation materials, and the vertical ribs are added to the traditional brick wall, which effectively increases the stability and thermal performance of the wall. The selected PCM concrete has better functions of heat storage and temperature regulation. The thermal performance test results show that the thermal insulation performance of $\mathrm{H}$ - shaped wall block is the best, which is due to the $\mathrm{H}$ - shaped wall block can effectively block the transverse thermal bridge effect of the wall, and the heat flow increases remarkably. The results of practical environmental monitoring on H-shaped concrete block show that there is a large temperature difference between the external wall and the internal wall, and the wall has better thermal insulation performance.
\end{abstract}

\section{INTRODUCTION}

With the rapid development of the global economy, the total energy consumption is increasing $[1,2]$. Building energy consumption occupies an important proportion in the overall energy consumption $[3,4]$. Indoor heating in winter and large use of air conditioning in summer are the reasons for high building energy consumption. Research and popularization of energy-saving buildings is an effective means to reduce energy consumption and environmental pollution [5].

Exterior wall, interior wall, doors and windows of buildings are the main factors leading to indoor energy consumption. Energy consumption from exterior wall accounts for $49 \%$ of the total consumption. Optimizing thermal insulation performance of exterior wall and improving thermal property of exterior wall are the most effective ways to avoid indoor energy consumption $[6,7]$. Technical transformation of external walls includes external/internal insulation upgrading and self-insulation technology of external walls. The external thermal insulation technology of the external wall is mainly used for the transformation of the old buildings, the air tightness and waterproof property of the wall body after the transformation are remarkably increased, but the durability and fire resistance are poorer [8-10]; The internal thermal insulation technology of the external wall is simple in construction and low in cost, but affects indoor decoration and occupies indoor usable floor area [11, 12]; the self-insulation technology of external wall has better durability and fire resistance, but the heat bridge effect cannot be avoided [13, 14]. On the basis of the above-mentioned traditional technologies, the researchers added fiber, fly ash, aerated concrete and so on to the concrete, which have improved the thermal performance of the building wall [15-19]; in recent years, new composite thermal insulation concrete walls (crosshole block concrete walls, composite ceramsite concrete walls, and hollow block concrete walls) have been widely used in various types of buildings [20,21], improving the thermal property of building walls to varying extent $[22,23]$. However, at present, the analysis of comprehensive thermal performance of the above-mentioned walls is relatively few, and the engineering application of the new-type composite concrete walls still lacks more theoretical bases [24, 25].

For the defects of temperature control performance and thermal property of existing concrete building walls, a new composite concrete wall block is proposed, and the thermal performance of the block is calculated and analyzed. The research conclusions can provide theoretical reference for the engineering application of composite concrete wall block.

\section{SPECIFICATION DESIGN AND THERMAL PERFORMANCE INDEX CALCULATION OF COMPOSITE CONCRETE BLOCK WALL}

\subsection{Design of concrete block wall}

In this study, two kinds of concrete block wall structures are designed, as shown in Figure 1, including Square -shaped and $\mathrm{H}$-shaped respectively. The block wall is mainly composed of horizontal hole, bottom plate, top plate, tie bar, mortar belt and vertical ribs from top to bottom. Heat insulating material can be embedded in the Cross-shaped cross holes of the block to further enhance the thermal performance of the building wall. For Square -shaped and $\mathrm{H}$-shaped block walls, vertical ribs are added based on the foundation of the traditional brick wall, which has greatly increased the stability of the wall. According 
to relevant building specifications, a single block is $240 \mathrm{~mm}$ long, $200 \mathrm{~mm}$ high, and $20 \mathrm{~mm}$ thick in ribs. The block shape is rounded rectangle with a radius of $20 \mathrm{~mm}$. The viod rate of block is $45 \%-53 \%$, and the single block is $7.98 \mathrm{~kg}-9.11 \mathrm{~kg}$ in weight, and $7.62 \mathrm{kN} / \mathrm{m}^{3}-9.86 \mathrm{kN} / \mathrm{m}^{3}$ in volume weight.

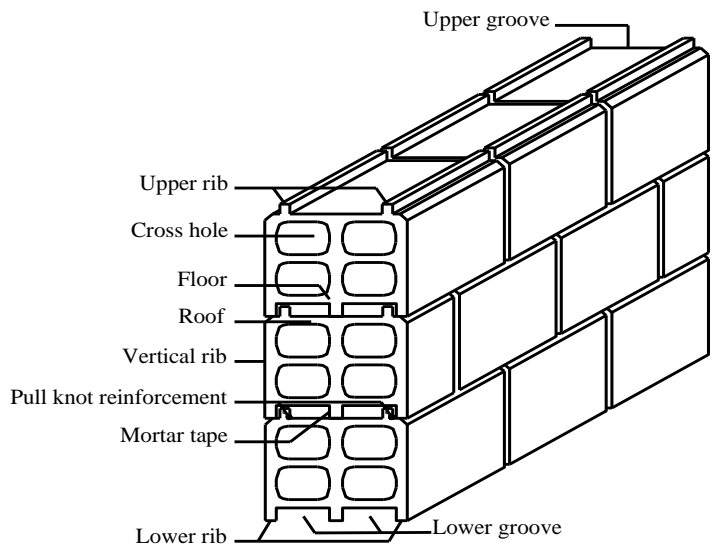

(a) Square -shaped

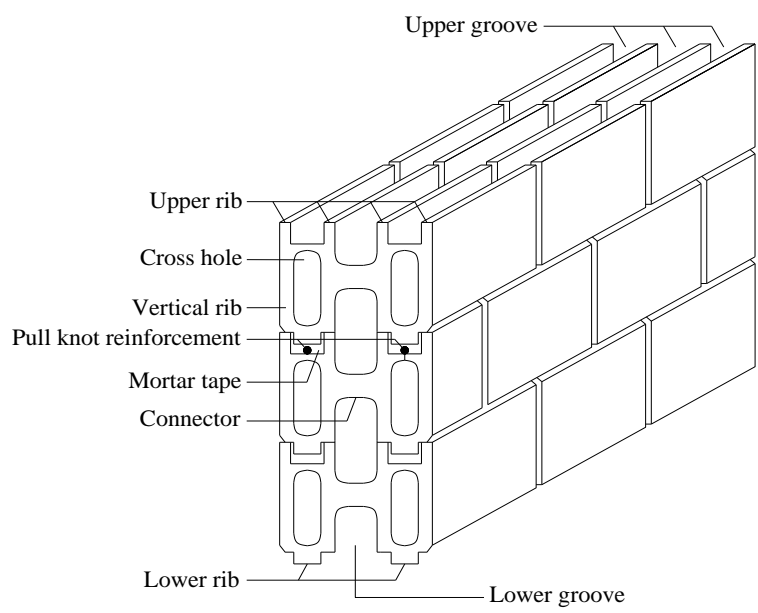

(b) $\mathrm{H}$-shaped

Figure 1. Concrete block wall structure

\subsection{Calculation of thermal performance index}

When there is temperature difference between inside and outside the building, the energy is transferred through the external wall. The heat transfer process is shown in Figure 2. The heat is conducted from the high temperature side to the low temperature side.

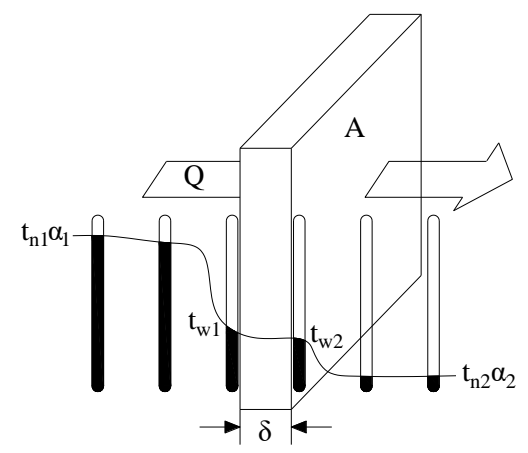

Figure 2. Heat transfer process

It is assumed that the wall area in the figure is $\mathrm{A}$, the heat passing through the wall is $\mathrm{Q}$, the wall thickness is $\delta$, the heat flux density is $\mathrm{q}$, and $\alpha_{1}$ and $\alpha_{2}$ are hear exchange coefficients respectively on both sides of the wall. $t_{w 1}$ and $t_{w 2}$ are wall surface temperature; and $t_{n 1}$ and $t_{n 2}$ are ambient temperature on both sides of the wall. The expressions of $\mathrm{Q}$ and $\mathrm{q}$ are respectively

$q=\frac{d Q_{\tau}}{d A d \tau}$

$Q=\frac{d Q_{\tau}}{d \tau}=\int_{A} q d A$

The expression for heat flow from left side to right side of the wall is successively:
$\left\{\begin{array}{l}Q_{1}=A \alpha_{1}\left(t_{n 1}-t_{w 1}\right) \\ Q_{2}=\frac{A \lambda}{\delta}\left(t_{w 1}-t_{w 2}\right) \\ Q_{3}=A \alpha_{2}\left(t_{w 2}-t_{n 2}\right)\end{array}\right.$

From Expression 3,

$Q=\frac{A\left(t_{n 1}-t_{n 2}\right)}{\frac{1}{\alpha_{1}}+\frac{\delta}{\lambda}+\frac{1}{\alpha_{2}}}$

The thermal resistance of wall block can be expressed as

$\bar{R}=\left[\frac{F_{0}}{\frac{F_{1}}{R_{o \cdot 1}}+\frac{F_{2}}{R_{o \cdot 2}}+\cdots+\frac{F_{n}}{R_{o \cdot n}}}-\left(R_{i}+R_{e}\right)\right] \varphi$

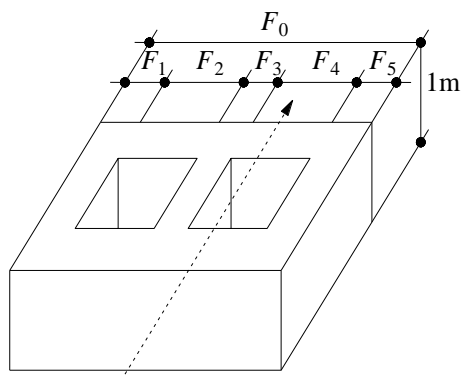

Figure 3. Schematic diagram for calculation of thermal resistance of wall blocks

$\mathrm{F}_{1}-\mathrm{F}_{\mathrm{n}}$ represents the heat transfer area in the heat flow direction, $\mathrm{F}_{0}$ is perpendicular to the direction of other areas; $\mathrm{R}_{\mathrm{o}-1}-\mathrm{R}_{\mathrm{o}-\mathrm{n}}$ represents heat transfer resistance corresponding to $\mathrm{F}_{1}-\mathrm{F}_{\mathrm{n}} ; \mathrm{R}_{\mathrm{i}}$ and $\mathrm{R}_{\mathrm{e}}$ represent the heat exchange resistance of the 
inner surface and the outer surface, respectively. The schematic diagram of Expression 5 is shown in Figure 3.

When the wall material is a uniform medium, its thermal resistance $\mathrm{R}$ and thermal inertia $\mathrm{D}$ are:

$\left\{\begin{array}{l}R=\delta / \lambda \\ D=R S\end{array}\right.$

$S$ and $\lambda$ are heat storage coefficient and heat transfer coefficient. The combined thermal resistance and thermal inertness of a multilayer medium can be expressed as:

$\left\{\begin{array}{l}R=R_{1}+R_{2}+\cdots+R_{n} \\ D=R_{1} S_{1}+R_{2} S_{2}+\cdots+R_{n} S_{n}\end{array}\right.$

The average heat storage coefficient and heat transfer coefficient at this time are converted into:

$\bar{\lambda}=\frac{\lambda_{1} F_{1}+\lambda_{2} F_{2}+\cdots \cdots+\lambda_{n} F_{n}}{F_{1}+F_{2}+\cdots \cdots+F_{n}}$

$\bar{S}=\frac{S_{1} F_{1}+S_{2} F_{2}+\cdots \cdots+S_{n} F_{n}}{F_{1}+F_{2}+\cdots \cdots+F_{n}}$

The specific size distribution of the concrete block structure is shown in Figure 4.

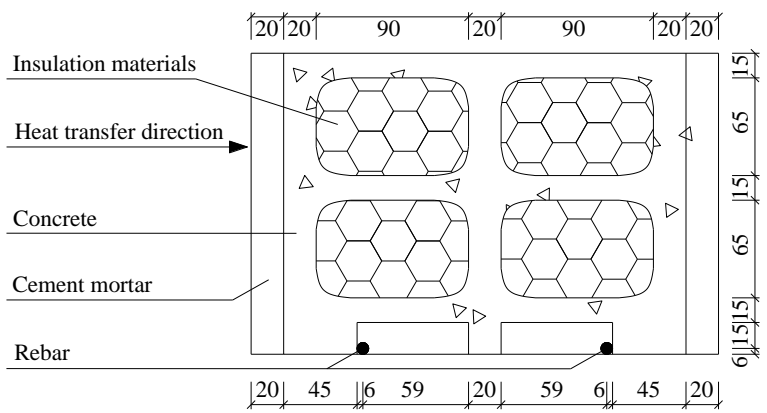

Figure 4. Specific size distribution of the concrete block

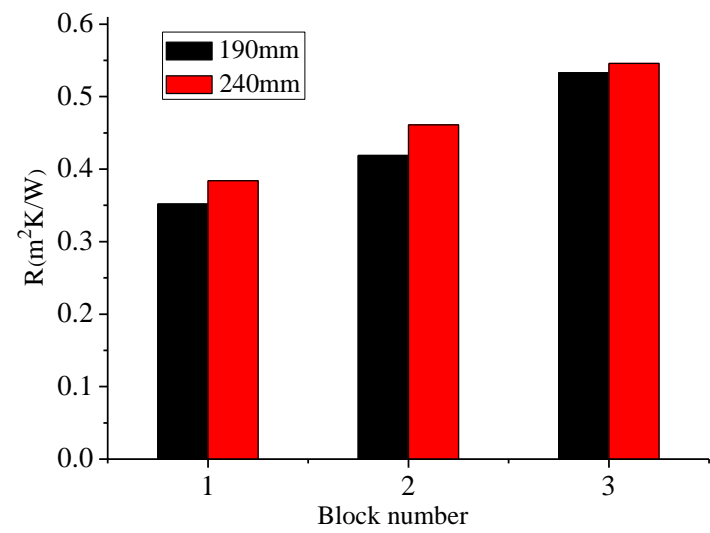

(a) Heat transfer resistance

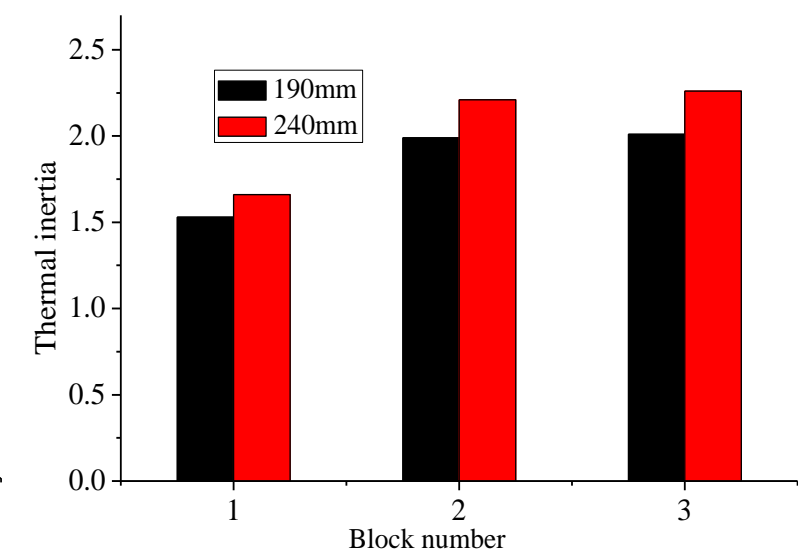

(b) Thermal inertia

\section{TEST RESULTS AND ANALYSIS}

The concrete selected in this study is paraffin phase change temperature control mortar concrete (PCM), which has better functions of heat storage and temperature regulation. The temperature field distribution of PCM concrete and ordinary concrete is tested with the results shown in Figure 5.

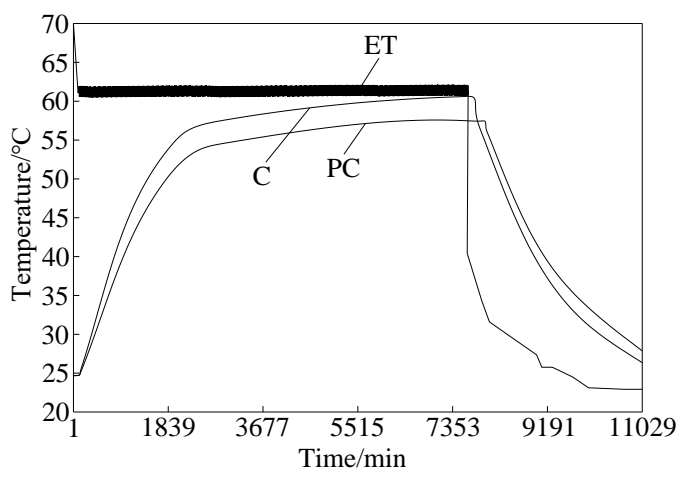

Figure 5. Temperature field distribution of two kinds of concrete

It can be seen from the figure that the ambient temperature is set at $62{ }^{\circ} \mathrm{C}$. The temperature field of PCM concrete used in this study is always lower than that of ordinary concrete in the pre-heating stage. When the ambient temperature decreases rapidly, the temperature field of PCM concrete decreases less than that of ordinary concrete. This is due to the fact that the PCM concrete releases the heat stored inside it after the ambient temperature has dropped. The curves in Figure 5 demonstrate that PCM concrete has better temperature control characteristics.

To further verify the Cross-shaped block wall and H-shaped block wall designed in this study, the two types of walls and the traditional Square-shaped walls are compared to calculate the heat transfer resistance and thermal inertia indexes of the three walls, and the calculation results are shown in Figure 6. The wall thickness $(190 \mathrm{~mm}$ and $240 \mathrm{~mm})$ of two walls is investigated, and the abscissa 1-3 represents the Squareshaped wall block, the Cross-shaped wall block and the Hshaped wall block, respectively.

Figure 6. Heat transfer resistance and thermal inertia of three types of concrete wall blocks

In order to analyze the accuracy of the results, all three types of wall blocks are not filled with thermal insulation materials. As shown in Figures. 6 (a) and 6 (b), R (Square-shaped) $<$ R
(Cross-shaped) < R (H-shaped); D (Square-shaped) $<\mathrm{D}$ (Cross-shaped) $<\mathrm{D}$ (H-shaped). The calculation results of two important evaluation indexes show that the thermal insulation 
performance of H-shaped wall blocks is the best, which is because H-shaped wall blocks can effectively block the transverse thermal bridge effect of the wall, and the heat flow increases remarkably.

$\mathrm{H}$-shaped wall blocks are selected to monitor the actual environment. Figure 7 shows the variation of the external surface, internal surface, mortar and block interface temperature of the building wall. Figure 8 shows the heat transfer coefficient of the wall. As can be seen from Figures 7 and 8 , the temperature difference between the external wall and internal inner wall is large, and the wall has better thermal insulation performance.

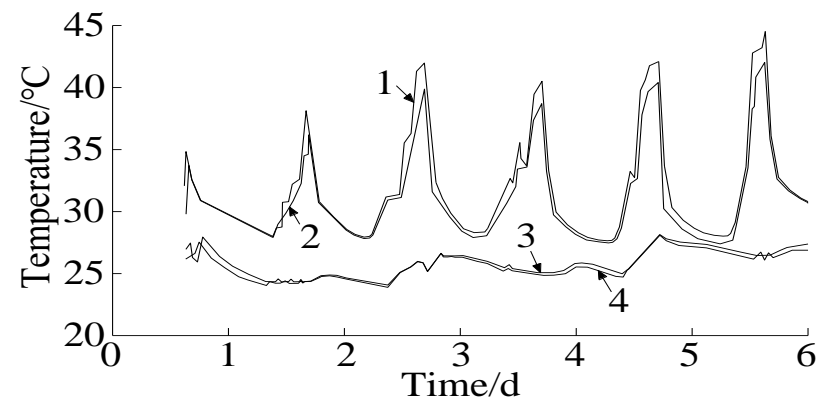

1-External wall surface temperature

2-Interfacial temperature of mortar and block on the outside of the wall

3-Wall surface temperature

4-Interfacial temperature of mortar and block inside wall

Figure 7. Temperature variation of each part of the wall

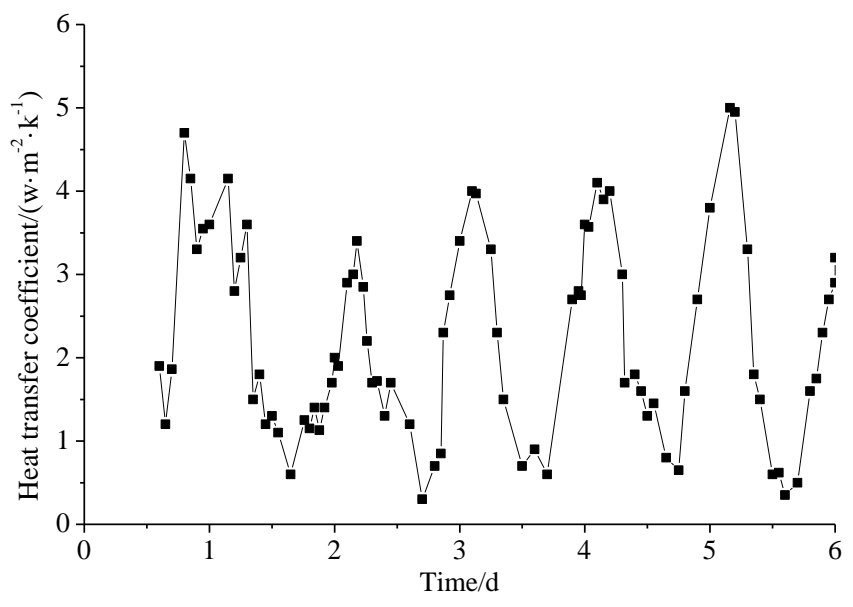

Figure 8. Wall heat transfer coefficient

\section{CONCLUSIONS}

For the defects of temperature control performance and thermal property of existing concrete building walls, a new composite concrete wall block is proposed, and the thermal property of the block is calculated and analyzed. The conclusions are as follows:

The the transverse hole of designed H-shaped concrete block can be embedded with thermal insulation materials, and the vertical ribs are added to the traditional brick wall, which effectively increases the stability and thermal performance of the wall.
The selected PCM concrete has better functions of heat storage and temperature regulation. The thermal performance test results show that the thermal insulation performance of $\mathrm{H}$ shaped wall block is the best, which is due to the $\mathrm{H}$ - shaped wall block can effectively block the transverse thermal bridge effect of the wall, and the heat flow increases remarkably. The results of practical environmental monitoring on $\mathrm{H}$-shaped concrete block show that there is a large temperature difference between the external wall and the internal wall, and the wall has better thermal insulation performance.

\section{ACKNOWLEDGEMENT}

Thanks are extended to projects: National Natural Science Foundation of China (51578446); Education Research Project of Shaanxi Provincial Department (15JK1488); Natural Basic Research Program of Shaanxi Province (2016JQ5090); Science and Technology Plan Project of Provincial Department of Housing and Urban Rural Development (2014$\mathrm{K} 11)$.

\section{REFERENCES}

[1] Zhou N, Lin J. (2008). The reality and future scenarios of commercial building energy consumption in china. Energy \& Buildings 40(12): 2121-2127. https://doi.org/10.2172/941175

[2] Cai WG, Wu Y, Zhong Y, Ren H. (2009). China building energy consumption: situation, challenges and corresponding measures. Energy Policy 37(6): 20542059. https://doi.org/10.1016/j.enpol.2008.11.037

[3] Zhao HX, Magoulès F. (2012). A review on the prediction of building energy consumption. Renewable \& Sustainable Energy Reviews 16(6): 3586-3592. https://doi.org/10.1016/j.rser.2012.02.049

[4] Neto AH, Fiorelli FAS. (2008). Comparison between detailed model simulation and artificial neural network for forecasting building energy consumption. Energy \& Buildings 40(12): 2169-2176. https://doi.org/10.1016/j.enbuild.2008.06.013

[5] Biswas MAR, Robinson MD, Fumo N. (2016). Prediction of residential building energy consumption: a neural network approach. Energy 117: 84-92. https://doi.org/10.1016/j.energy.2016.10.066

[6] Fumo N, Mago P, Luck R. (2010). Methodology to estimate building energy consumption using energyplus benchmark models. Energy \& Buildings 42(12): 23312337. https://doi.org/10.1016/j.enbuild.2010.07.027

[7] Li K, Su H, Chu J. (2011). Forecasting building energy consumption using neural networks and hybrid neurofuzzy system: a comparative study. Energy \& Buildings 43(10): 2893-2899. https://doi.org/10.1016/j.enbuild.2011.07.010

[8] Howard B, Parshall L, Thompson J, Hammer S, Dickinson J, Modi V. (2012). Spatial distribution of urban building energy consumption by end use. Energy \& Buildings 45: 141-151. https://doi.org/10.1016/j.enbuild.2011.10.061

[9] Tingley DD, Hathway A, Davison B. (2015). An environmental impact comparison of external wall insulation types. Building \& Environment 85(85): 182189. https://doi.org/10.1016/j.buildenv.2014.11.021 
[10] Guo SR. (2012). The application and developmental trend of exterior wall external insulation. Applied Mechanics \& Materials 174-177: 1367-1371. https://doi.org/10.4028/www.scientific.net/amm.174177.1367

[11] Florides GA, Tassou SA, Kalogirou SA, Wrobel LC. (2002). Measures used to lower building energy consumption and their cost effectiveness. Applied Energy 73(3-4): 299-328. https://doi.org/10.1016/s0140-6701(03)82133-1

[12] Ekici BB, Aksoy UT. (2009). Prediction of building energy consumption by using artificial neural networks. Advances in Engineering Software, 40(5): 356-362. https://doi.org/10.1016/j.advengsoft.2008.05.003

[13] Bouchair A. (2008). Steady state theoretical model of fired clay hollow bricks for enhanced external wall thermal insulation. Building \& Environment 43(10): $1603-1618$ https://doi.org/10.1016/j.buildenv.2007.10.005

[14] Cheng T, Yan KQ. (2011). Numerical simulation for the thermal stress of composite wall insulation system. Advanced Materials Research 168-170(6): 875-879. https://doi.org/10.4028/www.scientific.net/amr.168170.875

[15] MarÄiukaitis G, Jurk̈̈nas G. (2013). Possibilities of using sulphur and plant origin waste for light-weight and thermal insulation construction composites. Journal of Environmental Engineering $\backslash \mathrm{s} \& /$ slandscape Management 21(2): $106-113$ https://doi.org/10.3846/16486897.2013.767805

[16] Miao J, Tao J, Liu Y. (2015). Research on self-thermal insulation wall construction technology of autoclaved aerated concrete block. International Journal of Thermal Sciences 48(8): $1574-1585$ https://doi.org/10.2991/iccet-15.2015.202

[17] Zhou XJ, Song JK, Jiang XL, Xu DD. (2014). Experimental study on compressive mechanical performance of fly-ash thermal insulation hollow block masonry. Building Technique Development 488-489: 643-646.

https://doi.org/10.4028/www.scientific.net/amm.488489.643
[18] Li B, Yao R. (2009). Urbanisation and its impact on building energy consumption and efficiency in china. Renewable Energy 34(9): 1994-1998. https://doi.org/10.1016/j.renene.2009.02.015

[19] Masoso OT, Grobler LJ. (2008). A new and innovative look at anti-insulation behaviour in building energy consumption. Energy \& Buildings, 40(10): 1889-1894. https://doi.org/10.1016/j.enbuild.2008.04.013

[20] Yang M, Liang JG, Yang WJ. (2012). Aerated concrete composite reinforced concrete shear wall thermal insulation layer stress analysis and crack control. Applied Mechanics \& Materials 204-208: 3315-3324. https://doi.org/10.4028/www.scientific.net/amm.204208.3315

[21] Yang F, Sun LZ, Xie ZL. (2012). Theoretical study on optimal design of thermal performance of aerated concrete-based composite thermal insulation wall. Advanced Materials Research 450-451: 663-666. https://doi.org/10.4028/scientific5/amr.450-451.663

[22] Lesovik VS, Vorontsov VM., Glagolev ES, Pomochnicov DD, Voronov VV, Volodchenko AA. (2017). Increasing efficiency of composite thermal insulation foam concretes. International Conference "actual Issues of Mechanical Engineering. https://doi.org/10.2991/aime-17.2017.67

[23] Zhao S, Li FL, Yang S, Song LS. (2011). Thermal insulation behaviors of rinforced concrete composite wall with inner insulating layer. Advanced Materials Research 152-153: 395-398. https://doi.org/10.4028/www.scientific.net/amr.152153.395

[24] Li FL, Chen HN, Feng XZ, Yang S. (2013). Durability of concrete for thermal insulation composite wall. Applied Mechanics \& Materials 438-439: 314-317. https://doi.org/10.4028/www.scientific.net/amm.438439.314

[25] Ai L. (2016). Construction method of the new thermal insulation material foam concrete. International Conference on Management, Education, Information and Control. https://doi.org/10.2991/meici-16.2016.85 